SEÇÃO

RESENHAS 
Em vão com o mundo da floresta privas!...

- Todas as hermenêuticas sondagens, Ante o hieróglifo e o enigma das folhagens, São absolutamente negativas!

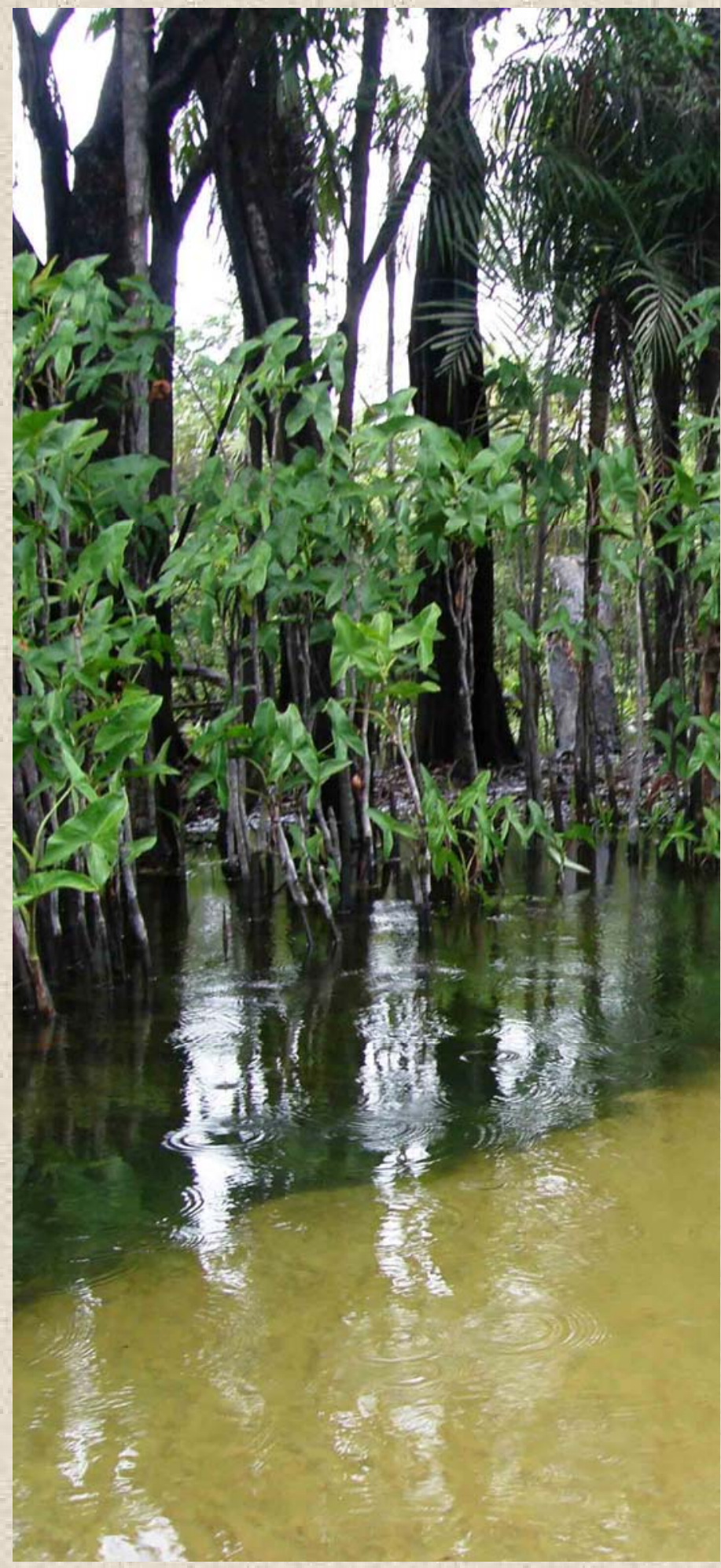

Araucárias, traçando arcos de ogivas, Bracejamentos de álamos selvagens, Como um convite para estranhas viagens, Tornam todas as almas pensativas!

Há uma força vencida nesse mundo! Todo o organismo florestal profundo É dor viva, trancada num disfarce...

Vivem só, nele, os elementos broncos, - As ambições que se fizeram troncos, Porque nunca puderam realizar-se!

(Augusto dos Anjos) 


\section{Seria o Rio de Janeiro uma referência para a Gestão Participativa em Unidades de Conservação? Andrea Rabinovici}

Irving, M.A.; Giuliani, G.M.; Loureiro, C.F.B.(orgs.). Parques Estaduais do Rio de

Janeiro: Construindo novas práticas para a gestão. São Carlos: Ed. RiMa, 2008.

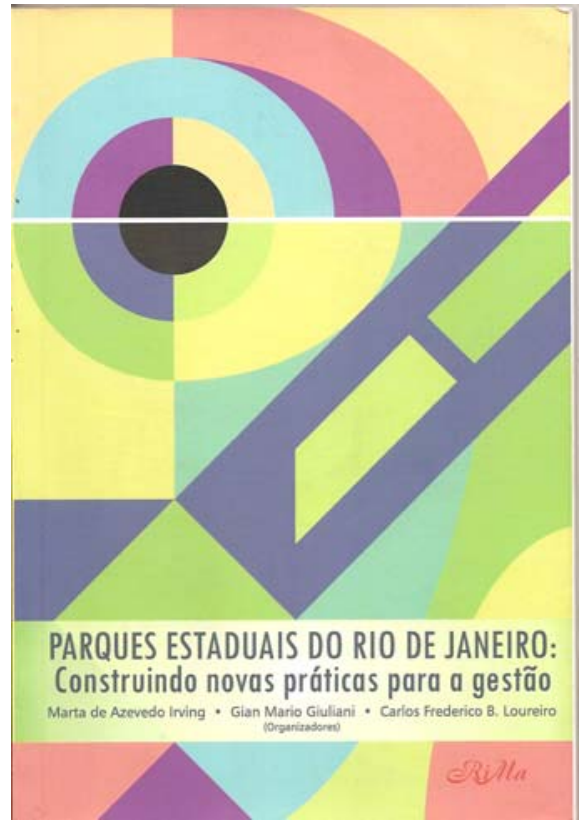

No ano de 2007, o Instituto Estadual de Florestas (IEF) ${ }^{1}$ do Estado do Rio de Janeiro criou o Programa de Fortalecimento de Conselhos de Unidade de Conservação com o objetivo, entre outros, de cumprir exigência da Lei $n^{\circ} 9.985 / 2000$, que instituiu o Sistema Nacional de Unidades de Conservação (SNUC) e atender diretrizes do Plano Estratégico Nacional de Áreas Protegidas (PNAP). É sobre este momento histórico das áreas protegidas deste Estado que se voltam os olhares da equipe de 31 pesquisadores do Grupo de Pesquisa "Biodiversidade, Áreas Protegidas e Inclusão Social" (GAPIS), vinculado ao Programa Eicos de PósGraduação da Universidade Federal do Rio de Janeiro, através do "Observatório de Áreas Protegidas do Rio de Janeiro", especialmente criado por eles para a tarefa.

Um dos primeiro resultados deste trabalho, foi a publicação, no final de 2008 pela Editora RiMa, do livro "Parques Estaduais do Rio de Janeiro: construindo novas práticas para a gestão", organizado por Marta de Azevedo Irving, Gian Mario Giuliani e Carlos Frederico Bernardo Loureiro. O livro possui uma ampla revisão bibliográfica e documental sobre as práticas participativas de gestão de Unidades de Conservação (UCs) e descreve os resultados de algumas idas a campo, nas quais foram realizadas entrevistas com seus gestores.

Os organizadores já possuem alguns trabalhos publicados que discutem a gestão das UCs, de modo que o livro se insere dentro de um contexto maior e faz parte de uma linha de pesquisa de importância fundamental para que sejam elaborados subsídios visando uma mudança de rumos que aponte para a efetiva participação da sociedade civil nesse processo. Desta forma, como afirmam os próprios organizadores, o livro, que almeja ter como público-alvo tanto o cidadão comum quanto os gestores, tem por objetivo integrar o pensamento acadêmico e a gestão pública das Unidades de Conservação. A pretensão final é a ilustração de caminhos possíveis para a gestão participativa, defendida, de forma bastante otimista, como uma nova maneira de pensar e agir sobre as áreas protegidas no país.

No primeiro capítulo, de autoria dos três organizadores, é apresentada uma ex- 
celente síntese sobre o histórico da formação da maneira tradicional com a qual as áreas protegidas vêm sendo geridas no Brasil e no mundo. Esta síntese serve como embasamento teórico para toda a argumentação apresentada no restante do livro. Concordando com ideias defendidas por Diegues (1996) sobre a existência do "mito perverso de natureza como obstáculo ao desenvolvimento", o livro tenta "desconstruir esse mito e provocar a alternativa de construção possível da gestão participativa de parques no Estado do Rio de Janeiro, em um cenário projetado de governança democrática" (p. XIX).

Sendo nitidamente influenciado pelo pensamento de Edgar Morin, o capítulo segue apresentando como se constituiu o modo de funcionamento e existência da sociedade contemporânea, fundamentado principalmente na ideia de disjunção absoluta entre sociedade e natureza, reforçada pelo modelo de desenvolvimento que transforma o meio natural em recurso. No domínio da sociedade capitalista as dimensões natural e social são submetidas exclusivamente à lógica mercantil e monetária, agravando a contraposição e dissociação sociedade-natureza. Para os organizadores, o diálogo entre as ciências humanas e as ciências da natureza parece ser inevitável em uma reflexão acadêmica que pretenda gerar conhecimentos para a transformação desta visão de sociedade e, consequentemente, das políticas públicas.

É essa a perspectiva a qual, historicamente, influenciou a criação da gestão de Unidades de Conservação no Brasil e no mundo e que tem provocado os incontáveis conflitos sociais daí advindos. No Brasil, onde está se popularizando uma crença de que todos os conflitos e os problemas podem ser resolvidos em um regime democrático e participativo, há que se ponderar que, se de fato isso ocorre, só poderia ser em uma perspectiva diferente, integradora, inerente ao pensamento complexo defendido por Morin (2008). Só assim seria possível a superação da "cisão histórica sociedadenatureza no sentido de uma nova lógica, resultando, provavelmente, em uma das faces mais inovadoras da reflexão sobre sustentabilidade" (p. 11).

Em contraponto ao cenário no qual não houve a participação da sociedade na criação e gestão das UCs, aliado à aprovação do SNUC, fortalecido pela perspectiva de implantação PNAP, os organizadores do livro acreditam que há boas perspectivas para que o Brasil possa cumprir os compromissos assumidos no contexto da Convenção da Diversidade Biológica. Esta sugere a gestão participativa das áreas protegidas, envolvendo Estado e sociedade. Essa realidade contagia todo o livro com uma visão bastante otimista desse novo momento histórico, principalmente aos caminhos escolhidos pelo IEF para alguns Parques Estaduais, com fins à construção de uma governança democrática dessas Unidades.

No segundo capítulo, alguns dos autores contextualizam a dimensão e a problemática da gestão de áreas protegidas perante os novos desafios surgidos com a aprovação do SNUC, do PNAP, e da Política Nacional de Desenvolvimento Sustentável de Povos e Comunidades Tradicionais (PNPCT - Decreto no 6.040/2007), instituída com o objetivo de também contribuir para a discussão dos direitos das populações tradicionais nas UCs. Em um primeiro levantamento, realizado através dos sites oficiais e de entrevistas com alguns gestores públicos, os autores apresentam uma tabela, bastante ilustrativa, com as 95 Unidades de Conservação do Estado do Rio de Janei- 
ro, além de um mapa com a localização das UCs mais importantes. Entre as alternativas que surgem para superar a fragmentação dos biomas e avançar no sentido de uma gestão mais participativa, a formação de mosaicos e corredores ecológicos começa a se consolidar, ainda que de maneira insipiente, no Estado.

O Instituto Estadual de Florestas coordena um Programa de Reestruturação de Conselhos de Unidade de Conservação, visando a consolidação dos conselhos consultivos como importantes arenas de participação social e explicitação de conflitos, abrindo o poder público, pela primeira vez, espaço para a participação social nos processos de gestão. É aqui que o Ecoturismo surge como uma das possibilidades de inserção das populações locais, pois essa atividade pode promover a geração de renda com oportunidades de trabalho para artesãos e guias locais, socorristas, recepcionistas, entre outros, legalmente contratados e envolvidos nas atividades vinculadas à conservação da natureza. Essa nova visão representa, para os autores, um avanço nas políticas de proteção da biodiversidade, sob a ótica da inclusão social.

Nos demais capítulos do livro (que vão do $3^{\circ}$ ao $8^{\circ}$ ) diversos autores do GAPIS sistematizam as informações disponíveis e discutem as particularidades dos mais importantes Parques Estaduais (P.E.), tendo como focos o momento atual de gestão e a projeção de alguns dos principais desafios no futuro. São eles: P.E. da llha Grande, P.E. Marinho do Aventureiro, P.E. da Serra da Tiririca, P.E. dos Três Picos, P.E. da Serra da Concórdia, P.E. da Pedra Branca e o P.E. do Desengano.

Para cada uma dessas UCs é apresentada contextualização histórica, socioeconômica e geográfica, além de uma caracterização da importância ecológica e as pressões sobre a base de recursos naturais, bem como um histórico da gestão com a análise das possibilidades e desafios para a participação das comunidades. Em todos os parques foram realizadas visitas a campo para o acompanhamento de atividades dos Conselhos Gestores recém-formalizados, de modo a construir um pequeno "Estado-da-Arte" dos mesmos, no contexto do Programa de Reestruturação.

O livro, nesse aspecto, se constitui em uma boa "porta de entrada" para o debate do futuro dos Parques Fluminenses, principalmente àqueles que buscam uma primeira leitura sobre sua problemática.

Alguns dos parques apresentados estão com seus processos de implantação em gestão em fase mais avançada; outros ainda em planejamento. A análise realizada pelos autores é precoce, tendo em vista que, na maioria dos parques estudados, o processo de implantação dos Conselhos é bastante recente.

No P.E. da Ilha Grande, por exemplo, a oficina de Diagnóstico Rápido Participativo (DRP), ocorreu em 2007, e a primeira oficina participativa para elaboração de proposta de zoneamento do Parque, apenas em agosto de 2008 (vale lembrar que o livro foi lançado poucos meses depois disso). No caso do P.E. da Serra da Tiririca, foi somente em novembro de 2008 que foram iniciados os trabalhos de recriação e fortalecimento do conselho, sendo pouco tempo, nos parece, para os autores defenderem que "o atual conselho consultivo está operando com regularidade e ampla participação, já em sua segunda composição" (p.54). De qualquer forma, um dos grandes méritos da obra é registrar esta fase inicial no qual se encontram esses processos, de 
modo que possam subsidiar futuras análises.

O pioneirismo em publicar dados compilados recentemente dos Parques do Rio de Janeiro confere ao livro um caráter de ser uma obra relativamente "datada". Isso é muito visível em várias passagens do texto, as quais revelam expectativas momentâneas e descrições de situações muito específicas.

Outra marca evidente nos capítulos que apresentam a situação dos parques é o otimismo com relação às perspectivas da gestão participativa e seu impacto no âmbito nacional. Apesar deste otimismo, há muita cautela quando se analisa o contexto conjunto das UCs, sendo que, para muitos casos, diversos desafios a serem enfrentados são apresentados com clareza. A própria população acredita que os programas governamentais podem apenas significar "fumaça sem fogo". Mesmo analisando o momento atual, são registrados pelos autores diversos pontos de fragilidade nas propostas de gestão participativa, sendo apontados alguns caminhos e cuidados a serem considerados no futuro.

Esse contexto dificulta o adequado planejamento e manejo do Ecoturismo no interior dos Parques, desestimulando o envolvimento das comunidades do entorno com as atividades econômicas sustentáveis possíveis, o que poderia se constituir em importante alternativa para a conservação da biodiversidade e inclusão social.

Os autores afirmam: o que acontece no Rio de Janeiro, e que é bastante recente para quaisquer conclusões, é similar ao que se dá em outros Estados do país, bem como internacionalmente. No Brasil continuamos atentos e partícipes nos debates, em suas idas e vindas constantes, ora pendendo para a proteção integral dos ecossistemas, ora para a conservação socioambiental. Seja qual for o ponto de partida, ainda estamos sem fôlego para o cuidado e os estudos sobre o entorno dos Parques, nos quais se aglomeram pessoas, inclusive os excluídos pela própria conservação, os quais transformam as paisagens, por vezes piorando, noutras até melhorando a qualidade ambiental em volta das UCs.

A participação e a inclusão social nas áreas protegidas são ainda pouco questionadas e criticadas, e, podem gerar, segundo os autores: "leitura simplificada do processo de gestão, muito mais como uma formalidade e menos como responsabilidade de construção de um processo dialógico para o delineamento de pactos sociais duradouros, capazes de internalizar interesses individuais e, principalmente, coletivos" ( $p$. 109).

Precisamos de tempo para praticar a participação, a democracia e, assim poder criticar e melhorá-la. Assim, uma mudança como a que se propõe com as leis, em escala internacional, necessita de tempo e de força para ser capaz de ser internalizada e influenciar novos rumos na gestão de áreas protegidas e seus entornos. Os autores enfatizam que este processo "representa nitidamente um processo de 'contracultura"' (p. 110).

Apesar do pouco tempo de prática e de estudos, os pesquisadores arriscam conclusões e tendências: há que se provocar questionamentos que contribuam com a construção de alternativas teóricas e metodológicas para a gestão de parques no país; a criação nada democrática das UCs brasileiras ainda é responsável pelos desdobramentos pouco democráticos dos mesmos e dos conflitos decorrentes; a importân- 
cia de se criar metodologias capazes de promover o envolvimento de diversos atores sociais na gestão das UCs, bem como na sua avaliação; cada um dos atores deve atuar de acordo com a categoria a qual representa, imbuído de autoridade e legitimidade atribuídas por seus pares, bem como deverá assumir responsabilidades concretas; e o Plano de Manejo deve ter uma força e dinâmica legitimadas por acordos e pactos entre os partícipes e seus saberes de forma que tenha dinâmica e vitalidade para que, mais do que um documento, ser uma referência aos que cuidam de determinada área.

Afora isso, os pesquisadores ainda observam que a gestão deve assumir contornos mais pragmáticos e próximos da realidade local; precisam ser continuamente avaliados para poderem ganhar força sem serem banalizados.

Segundo os autores, o momento político do Rio de Janeiro favorece o processo participativo. Apesar de ser uma afirmação datada, da qual todos sabemos as possíveis consequências, de fato, o que temos de oportuno é a criação de todo um aparato participativo, que merece ser cuidadosamente estudado. Os colegas do RJ estão fazendo isso, com a formação de uma força-tarefa que inclui pesquisadores, estudantes, técnicos e outros interessados, e isso sim é mais do que oportuno, positivo e necessário. O diálogo com estudos em outras localidades para que se observem padrões e haja um aprendizado potencializado é extremamente recomendado. O RJ com este amplo projeto de pesquisa, este otimismo, com as promessas registradas no livro (de que serão concebidos ainda de um site e um filme sobre a gestão participativa em parques), tornam o Estado, pioneiro ou não na gestão participativa. Aguardaremos ansiosos pelos resultados e pela interação dialógica durante o processo!

\section{Referências Bibliográficas}

DIEGUES, A. C. O mito moderno da natureza intocada. São Paulo: NUPAUB/ Universidade de São Paulo, 1996.

MORIN, E. On complexity. New York: Hampton Press, 2008.

NOTA

${ }^{1}$ Atualmente este órgão denomina-se Instituto Estadual do Ambiente (INEA).

Andréa Rabinovici: Universidade Federal de São Carlos - UFSCar, Campus Sorocaba, Núcleo de Estudos e Pesquisas Ambientais - Universidade Estadual de Campinas - UNICAMP

Email: andrea@ufscar.br

Link para o currículo Lattes: http://lattes.cnpq.br/4506171831521594

Data de submissão: 14 de maio de 2009

Data de aceite: 25 de maio de 2009 